\title{
FAKTOR CAMPUR KOD DALAM KALANGAN MASYARAKAT IBAN DI SARAWAK
}

\author{
Code-Mixing Factor among the Iban Community in Sarawak \\ Corella Anak Stephen \\ corella.stephen@ipgm.edu.my \\ Chemaline Anak Osup \\ chemaline@fbk.upsi.edu.my \\ Siti Saniah Abu Bakar \\ saniah@fbk.upsi.edu.my \\ Universiti Pendidikan Sultan Idris
}

\begin{abstract}
ABSTRAK
Objektif kajian ini ialah untuk menyelidiki faktor dominan yang mendorong situasi campur kod masyarakat Iban di Sarawak. Kajian ini menggunakan pendekatan kuantitatif, dan data kajian diperoleh melalui teknik rakaman spontan dan soal selidik. Sampel kajian terdiri daripada individu dan kelompok masyarakat Iban yang berpendidikan Inggeris dan berpendidikan Melayu. Situasi campur kod dalam komunikasi masyarakat Iban didorong oleh faktorfaktor dominan yang diwakili oleh akronim 'KOMUNIKASI', iaitu kecekapan berbahasa, orang, minat, ungkapan yang panjang, niat, implikasi pembelajaran, kefahaman mesej, amalan, situasi dan istilah. Kesimpulannya, situasi campur kod dalam komunikasi masyarakat Iban masih dalam keadaan yang terkawal. Implikasi kajian menunjukkan situasi campur kod dalam komunikasi masyarakat Iban ini mampu membawa perkembangan yang positif kepada bahasanya jika dilakukan dengan tujuan yang positif.
\end{abstract}

Kata kunci: faktor, dominan, campur kod, masyarakat Iban, akronim KOMUNIKASI

\begin{abstract}
The objective of this research is to investigate the domain that leads to code-mixing practices among the Iban community in Sarawak. Quantitative approach is used in this research and the research data was collected through spontaneous recordings and questionnaires. The research samples are individuals and groups of the Iban communities of whom have studied in the English and Malay medium of instruction. Code-mixing in the Iban community communication is driven by the domain factors that represents the accronym 'COMMUNICATION, such as kecekapan berbahasa, orang, minat, ungkapan yang panjang, niat, implikasi pembelajaran, kefahaman mesej, amalan, situasi and istilah. In conclusion, code-mixing in communication among the Iban community is still very much under control. The research implication showed that code-mixing in the Iban community communication is able to bring positive impact to the language when used with positive intentions.
\end{abstract}

Keywords: factor,dominant, code-mixing, Iban community, KOMUNIKASI acronym

\section{PENGENALAN}

Latar belakang penduduk Sarawak yang mengetahui tiga atau empat bahasa menunjukkan bahawa situasi campur kod sememangnya telah berlaku dalam pertuturan seharian mereka. Situasi campur kod semakin mewarnai pertuturan seharian mereka dengan wujudnya sistem pendidikan, iaitu melalui pembelajaran bahasa kedua, khasnya bahasa Melayu dan bahasa Inggeris di sekolah. Penggunaan bahasa Inggeris sebagai bahasa pengantar dalam sistem pendidikan pada awalnya, dan diikuti oleh bahasa Melayu pada era seterusnya, telah menyebabkan penduduk-penduduk di Sarawak yang mendapat pendidikan ini menguasai kedua-dua bahasa tersebut dengan baik. Justeru, campur aduk antara bahasa ibunda dengan bahasa kedua yang telah mereka pelajari secara formal, semakin kerap berlaku dalam pertuturan mereka. 
Lantas, kajian harus dijalankan untuk mengetahui faktor-faktor lain yang dominan dalam mempengaruhi situasi campur kod serta fungsi campur kod dilakukan dalam pertuturan masyarakat Iban perlu dikenal pasti.

Fasold (1984) menyatakan bahawa hal pertama yang kita fikirkan apabila kita memikirkan bahasa adalah "bahasa keseluruhan" (whole languages) atau multilingual, mengujarkan dua bahasa atau lebih dan harus menetapkan yang mana perlu digunakan. Tiga jenis pilihan yang dapat dilakukan, pertama alih kod, iaitu menggunakan satu bahasa pada satu keperluan, dan menggunakan satu bahasa yang lain pada keperluan lain. Kedua ialah campur kod, iaitu menggunakan satu bahasa tertentu dengan dicampuri serpihan-serpihan dari bahasa lain. Ketiga, dengan memilih satu variasi bahasa yang sama.

\section{PERSOALAN DAN OBJEKTIF KAJIAN}

Kebiasaan sesetengah penutur jati menggunakan campur kod dalam perbualan seharian mereka dianggap sebagai suatu tindakan yang boleh merosakkan ketulenan bahasa ibunda. Sesetengahnya menamakan situasi campur kod ini sebagai bahasa rojak. Oleh itu, persoalan kajian ini ialah apakah faktor-faktor dominan yang menyebabkan berlakunya situasi campur kod dalam komunikasi bahasa Iban? Objektif kajian ini pula adalah untuk menganalisis faktor dominan yang mendorong situasi campur kod dalam komunikasi bahasa Iban.

\section{KAJIAN LITERATUR}

Pada dasarnya, kajian campur kod ini dijalankan berdasarkan aspek sosiolinguistik yang melihat perkaitan antara pemilihan bahasa dengan faktor sosiobudaya dan pertuturan individu serta fungsi bahasa. Pengkaji meneliti sebahagian besarnya aspek sosiolinguistik yang menyebabkan berlakunya situasi campur kod dalam masyarakat Iban. Kajian yang dijalankan lebih menjurus kepada aspek sosiolinguistik untuk mencari jawapan kepada persoalan berkaitan situasi campur kod dalam bahasa Iban yang dituturkan oleh penutur jati bahasa Iban di Sarawak. Asmah Hj. Omar (1982) mendapati bahawa alih kod antara bahasa Melayu dan bahasa Inggeris sangat kerap dilakukan dalam situasi formal seperti dalam mesyuarat rasmi, manakala dalam situasi tidak formal pula, alih kod antara bahasa Melayu, bahasa Inggeris dan bahasa ibunda yang lain seperti bahasa Tamil, Kantonis serta dialek Melayu dikenal pasti sering dilakukan oleh masyarakat Malaysia secara umum.

Ghazali (1998), menunjukkan bahawa penutur yang seimbang penguasaannya dalam kedua-dua bahasa akan melakukan alih kod lebih kerap berbanding campur kod. Penutur tersebut juga didapati lebih cenderung melakukan alih kod untuk subjek dan objek ayat, manakala untuk predikat ayat, penutur lebih gemar melakukan campur kod dengan bahasa Inggeris.

Dalam kajian ini juga, pengkaji tidak membezakan alih kod, penukaran kod, perpindahan kod dan seumpamanya dengan campur kod kerana pengkaji bersetuju dengan pendapat beberapa ahli linguistik seperti Pakir (1989) yang meletakkan campur kod dalam rangkuman alih kod.

\section{METODOLOGI}

Kajian ini pada keseluruhannya akan menggunakan reka bentuk kajian explanatory sesuatu perkara atau isu, terutamanya yang baharu atau belum dibuat kajian (Babbie, 1998; Sekaran, 2003), yang melibatkan pengumpulan set data daripada satu kumpulan subjek yang bertujuan untuk menentukan kewujudan hubungan antara data dalam penyelidikan (Tuckman, 1972). Penggunaan kaedah ini ialah untuk mendapatkan maklumat yang jelas, tepat dan memahami pernyataan masalah dengan lebih baik berbanding dengan hanya menjalankan satu kaedah sahaja (Creswell dan Clark, 2007). Pengkaji mengumpul data primer daripada sampel yang sedia ada yang dikenal pasti sebagai responden.

Populasi untuk kajian ini terdiri daripada kaum Iban yang menetap di Sarawak. Untuk persampelan soal selidik, sampel kajiannya seramai 1095 orang responden yang berbangsa Iban, dan individu yang berpendidikan Inggeris dan Melayu. Untuk sampel rakaman, sampelnya ialah individu yang berbangsa Iban, yang pelbagai peringkat umurnya dan pelbagai latar belakang pendidikannya. Untuk 
mendapatkan sampel rakaman, penyelidik menggunakan persampelan mudah (convenience sampling), yang melibatkan 14 sesi rakaman.

\section{FAKTOR-FAKTOR YANG MEMPENGARUHI SITUASI CAMPUR KOD DALAM BAHASA IBAN}

Pengkaji telah mengenal pasti beberapa faktor yang mendorong penutur jati bahasa Iban melakukan campur kod, iaitu berdasarkan akronim 'KOMUNIKASI', yang kemudiannya pengkaji namakan sebagai Model KOMUNIKASI. Rajah 1 menunjukkan faktor-faktor berkenaan.

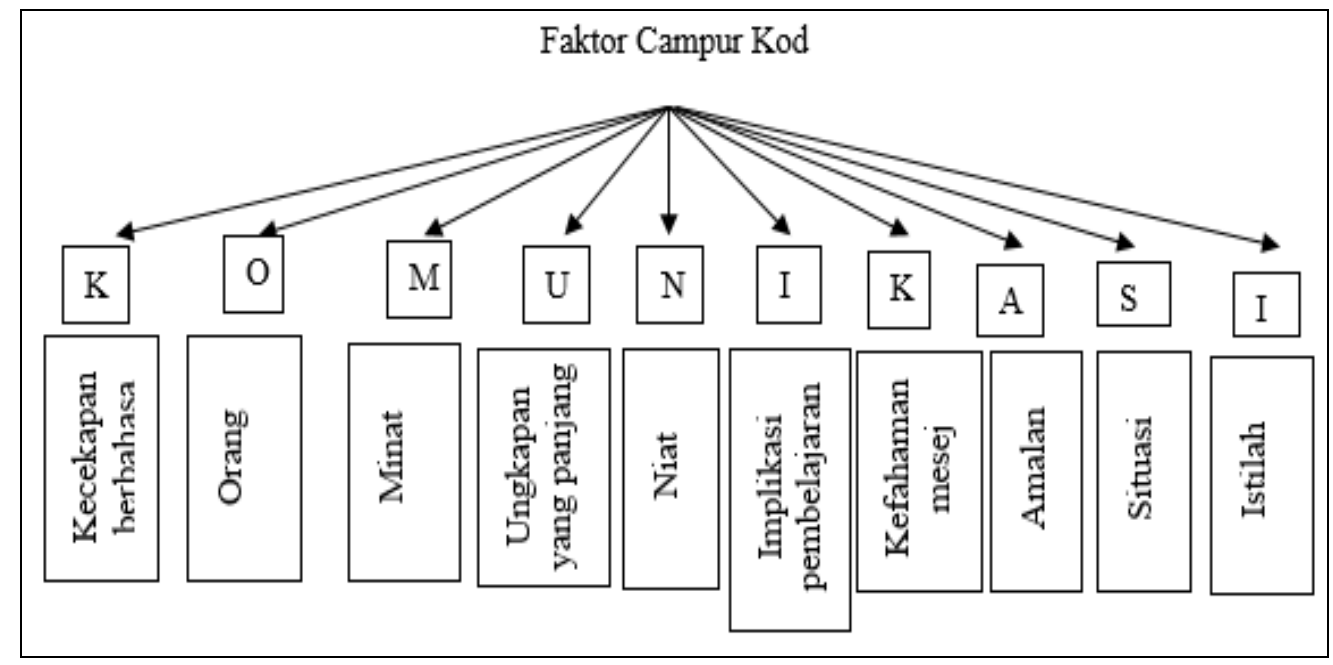

RAJAH 1 Model KOMUNIKASI

Faktor-faktor yang diwakili oleh akronim 'KOMUNIKASI' ini merupakan faktor-faktor yang mendorong penutur-penutur jati bahasa Iban melakukan campur kod dalam perbualan seharian mereka. Setiap huruf dalam perkataan 'KOMUNIKASI' melambangkan faktor yang mendorong campur kod berlaku dalam pertuturan mereka ataupun singkatan kepada komponen komunikasi yang berbeza. Pengkaji mengenal pasti 10 faktor yang mempengaruhi situasi campur kod dalam ujaran bahasa Iban dan memutuskan untuk menggunakan singkatan 'KOMUNIKASI' agar mudah untuk diingati. Faktor-faktor yang diwakili oleh akronim 'KOMUNIKASI' ini ialah kecekapan berbahasa, orang, minat, ungkapan yang panjang, niat, implikasi pembelajaran, kefahaman mesej, amalan, situasi dan istilah. Pendekatan ini diubahsuai daripada pendekatan yang digunakan oleh Hymes (1973) dalam membahaskan komponen tutur sehingga terhasilnya akronim SPEAKING untuk menandakan faktor-faktor yang wujud dalam sesuatu komunikasi. Setiap huruf dalam akronim tersebut merupakan komponen-komponen tutur yang harus ada dalam sesuatu komunikasi. Menurut Hymes (1973), akronim SPEAKING ialah setting, participants, ends, act sequences, key, instrumentalities, norms dan genres.

Jadual 1 menunjukkan analisis data soal selidik berhubung faktor-faktor yang mempengaruhi situasi campur kod masyarakat Iban. Situasi campur kod ini berlaku atas faktor-faktor tertentu. Berdasarkan data soal selidik didapati tujuh daripada 10 faktor yang dinyatakan berada pada tahap tinggi, dengan min purata melebihi 3.66, manakala tiga daripada faktor tersebut pula berada pada tahap sederhana. Tujuh faktor yang berada pada tahap tinggi ialah faktor ungkapan yang panjang, faktor niat, faktor implikasi pembelajaran, faktor kefahaman mesej, faktor amalan, faktor situasi dan faktor istilah. Tiga faktor yang berada pada tahap sederhana pula ialah faktor kecekapan berbahasa, faktor orang dan faktor minat. Oleh itu, jelaslah bahawa 10 faktor yang dinyatakan berdasarkan akronim 'KOMUNIKASI', merupakan faktor-faktor yang amat mempengaruhi situasi campur kod dalam komunikasi masyarakat Iban. 
JADUAL 1 Faktor-Faktor yang Mendorong Situasi Campur Kod Bahasa Iban

\begin{tabular}{|c|c|c|c|c|c|c|c|}
\hline \multirow{2}{*}{ Faktor-Faktor Campur Kod } & \multicolumn{5}{|c|}{$\underline{\text { Frekuensi dan Peratusan }(\%)}$} & \multirow{2}{*}{ Min } & \multirow[t]{2}{*}{ Tahap } \\
\hline & STS & TS & $\mathbf{T P}$ & $\mathbf{S}$ & SS & & \\
\hline $\begin{array}{l}\text { Kecekapan Berbahasa (K) } \\
\text { Menggunakan kata bahasa Melayu } \\
\text { atau bahasa Inggeris sewaktu } \\
\text { bertutur dalam bahasa ibunda } \\
\text { kerana saya fasih dalam bahasa } \\
\text { tersebut }\end{array}$ & $\begin{array}{c}56 \\
(5.4)\end{array}$ & $\begin{array}{c}110 \\
(10.6)\end{array}$ & $\begin{array}{c}223 \\
(21.5)\end{array}$ & $\begin{array}{c}465 \\
(44.9)\end{array}$ & $\begin{array}{c}181 \\
(17.5)\end{array}$ & 3.58 & Sederhana \\
\hline $\begin{array}{l}\text { Orang (O) } \\
\text { Menggunakan kata bahasa Melayu } \\
\text { atau bahasa Inggeris dalam bahasa } \\
\text { ibunda saya apabila saya berbual } \\
\text { dengan rakan-rakan sebaya }\end{array}$ & $\begin{array}{c}46 \\
(4.4)\end{array}$ & $\begin{array}{c}125 \\
(12.1)\end{array}$ & $\begin{array}{c}171 \\
(16.5)\end{array}$ & $\begin{array}{c}500 \\
(48.3)\end{array}$ & $\begin{array}{c}193 \\
(18.6)\end{array}$ & 3.65 & Sederhana \\
\hline $\begin{array}{l}\text { Minat (M) } \\
\text { Berasa bangga dan berminat untuk } \\
\text { menggunakan kata bahasa Melayu } \\
\text { atau bahasa Inggeris dalam bahasa } \\
\text { ibunda saya apabila saya berbual }\end{array}$ & $\begin{array}{c}56 \\
(5.4)\end{array}$ & $\begin{array}{c}143 \\
(13.8)\end{array}$ & $\begin{array}{c}216 \\
(20.9)\end{array}$ & $\begin{array}{c}417 \\
(40.3)\end{array}$ & $\begin{array}{c}203 \\
(19.6)\end{array}$ & 3.55 & Sederhana \\
\hline $\begin{array}{l}\text { Ungkapan yang Panjang (U) } \\
\text { Menggunakan kata bahasa Melayu } \\
\text { atau bahasa Inggeris dalam bahasa } \\
\text { ibunda saya untuk memendekkan } \\
\text { ungkapan dalam bahasa ibunda }\end{array}$ & $\begin{array}{c}46 \\
(4.4)\end{array}$ & $\begin{array}{c}115 \\
(11.1)\end{array}$ & $\begin{array}{c}175 \\
(16.9)\end{array}$ & $\begin{array}{c}462 \\
(44.6)\end{array}$ & $\begin{array}{c}237 \\
(22.9)\end{array}$ & 3.70 & Tinggi \\
\hline $\begin{array}{l}\text { Niat }(\mathbf{N}) \\
\text { Berasa bangga menguasai bahasa } \\
\text { Melayu atau bahasa Inggeris }\end{array}$ & $\begin{array}{c}29 \\
(2.8)\end{array}$ & $\begin{array}{c}66 \\
(6.4)\end{array}$ & $\begin{array}{c}133 \\
(12.9)\end{array}$ & $\begin{array}{c}487 \\
(47.1)\end{array}$ & $\begin{array}{c}320 \\
(30.9)\end{array}$ & 3.97 & Tinggi \\
\hline $\begin{array}{l}\text { Implikasi Pembelajaran (I) } \\
\text { Kebiasaan menggunakan kata } \\
\text { bahasa Melayu atau bahasa } \\
\text { Inggeris dalam bahasa ibunda } \\
\text { berlaku kerana sudah biasa } \\
\text { menggunakan bahasa tersebut sejak } \\
\text { alam persekolahan dahulu }\end{array}$ & $\begin{array}{c}25 \\
(2.4)\end{array}$ & $\begin{array}{c}72 \\
(7.0)\end{array}$ & $\begin{array}{c}145 \\
(14.0)\end{array}$ & $\begin{array}{c}466 \\
(45.0)\end{array}$ & $\begin{array}{c}327 \\
(31.6)\end{array}$ & 3.96 & Tinggi \\
\hline $\begin{array}{l}\text { Kefahaman Mesej }(\mathbf{K}) \\
\text { Meminjam kata bahasa Melayu } \\
\text { atau bahasa Inggeris ke dalam } \\
\text { bahasa ibunda supaya perkara yang } \\
\text { saya cuba sampaikan lebih jelas }\end{array}$ & $\begin{array}{c}34 \\
(3.3)\end{array}$ & $\begin{array}{c}84 \\
(8.1)\end{array}$ & $\begin{array}{c}185 \\
(17.9)\end{array}$ & $\begin{array}{c}494 \\
(47.7)\end{array}$ & $\begin{array}{c}238 \\
(23.0)\end{array}$ & 3.79 & Tinggi \\
\hline $\begin{array}{l}\text { Amalan (A) } \\
\text { Menggunakan kata bahasa Melayu } \\
\text { atau bahasa Inggeris dalam bahasa } \\
\text { ibunda tanpa saya sedari }\end{array}$ & $\begin{array}{c}46 \\
(4.4)\end{array}$ & $\begin{array}{c}85 \\
(8.2)\end{array}$ & $\begin{array}{c}216 \\
(20.9)\end{array}$ & $\begin{array}{c}449 \\
(43.4)\end{array}$ & $\begin{array}{c}239 \\
(23.1)\end{array}$ & 3.72 & Tinggi \\
\hline $\begin{array}{l}\text { Situasi }(\mathbf{S}) \\
\text { Selalu menggunakan kata bahasa } \\
\text { Melayu atau bahasa Inggeris dalam } \\
\text { bahasa ibunda apabila saya berbual- } \\
\text { bual dengan rakan-rakan }\end{array}$ & $\begin{array}{c}38 \\
(3.7)\end{array}$ & $\begin{array}{c}104 \\
(10.0)\end{array}$ & $\begin{array}{c}175 \\
(16.9)\end{array}$ & $\begin{array}{c}477 \\
(46.1)\end{array}$ & $\begin{array}{c}241 \\
(23.3)\end{array}$ & 3.75 & Tinggi \\
\hline $\begin{array}{l}\text { Istilah (I) } \\
\text { Selalu menggunakan kata bahasa } \\
\text { Melayu atau bahasa Inggeris dalam } \\
\text { bahasa ibunda untuk mengatasi } \\
\text { masalah peristilahan }\end{array}$ & $\begin{array}{c}27 \\
(2.6)\end{array}$ & $\begin{array}{c}89 \\
(8.6)\end{array}$ & $\begin{array}{c}144 \\
(13.9)\end{array}$ & $\begin{array}{c}441 \\
(42.6)\end{array}$ & $\begin{array}{c}334 \\
(32.3)\end{array}$ & 3.93 & Tinggi \\
\hline
\end{tabular}

*STS=Sangat tidak setuju, TS=Tidak setuju, TP=Tidak pasti, $\mathrm{S}=$ Setuju, $\mathrm{SS}=$ Sangat setuju

Berdasarkan data rakaman pula, didapati tujuh daripada 10 faktor campur kod dalam komunikasi bahasa Iban yang disenaraikan, mempengaruhi situasi campur kod dalam perbualan masyarakat Iban. 
Faktor-faktor campur kod dalam komunikasi bahasa Iban yang mempengaruhi situasi campur kod dalam perbualan masyarakat Iban berdasarkan data rakaman ialah kecekapan berbahasa, ungkapan yang panjang, implikasi pembelajaran, ketepatan mesej, amalan, situasi dan istilah. Data rakaman tersebut juga menunjukkan bahawa faktor kecekapan berbahasa, faktor implikasi pembelajaran, faktor amalan dan faktor situasi adalah paling dominan dan hadir dalam setiap sesi perbualan, diikuti faktor istilah, faktor ungkapan yang panjang dan ketepatan mesej.

Faktor kecekapan berbahasa hadir dalam semua rakaman sesi perbualan disebabkan semua responden menguasai dan dapat bertutur dalam bahasa Melayu dan bahasa Inggeris. Meskipun tahap penguasaan bahasa-bahasa tersebut pada tahap yang kurang mahir, terutamanya bahasa Inggeris, namun penguasaan beberapa istilah dalam bahasa berkenaan sudah mampu untuk mewujudkan situasi campur kod dalam perbualan seharian mereka. Namun, situasi campur kod menjadi lebih kerap dalam perbualan masyarakat Iban sekiranya si penutur mahir atau menguasai bahasa-bahasa tersebut dengan baik. Hal ini menunjukkan bahawa seseorang penutur itu akan melakukan campur kod dalam pertuturannya, tanpa mengira tahap kecekapan bahasanya lemah atau baik.

Faktor implikasi pembelajaran juga adalah antara faktor yang dominan dalam mempengaruhi situasi campur kod dalam komunikasi masyarakat Iban. Kebanyakan responden mempunyai latar belakang pendidikan, sama ada dalam aliran bahasa Inggeris atau bahasa Melayu. Pendedahan bahasa kedua secara formal membolehkan seseorang responden itu menguasai bahasa-bahasa yang dipelajarinya, dan menjadi mahir dalam bahasa-bahasa tersebut. Jika tidak menjadi mahir pun sekurang-kurangnya mengetahui beberapa istilah atau perbendaharaan kata dalam bahasa-bahasa berkenaan, dan seterusnya boleh menyumbang kepada situasi campur kod dalam komunikasi. Dalam Teori Monitor, mekanisme mental memproses dan menyusun bahasa yang didedahkan kepada pelajar. Proses-proses ini menyebabkan perlakuan lisan pelajar melakukan situasi campur kod (Noor Aina, 2007).

Data kajian menunjukkan bahawa semua responden telah mendapat pendidikan formal, sama ada di peringkat sekolah rendah, sekolah menengah mahupun di peringkat universiti, dan telah bersekolah di sekolah aliran Inggeris dan juga aliran Melayu. Hal ini jelas menunjukkan bahawa mereka semestinya mampu menguasai lebih daripada satu bahasa, selain bahasa ibunda mereka. Semasa mendapat pendidikan formal di sekolah, sudah semestinya mereka akan mempelajari bahasa lain, iaitu bahasa Melayu dan bahasa Inggeris. Kemahiran berbahasa dalam bahasa lain ini secara tidak langsung akan memberi kesan kepada bahasa ibunda mereka. Perkataan bahasa lain akan mula hadir dalam ayat-ayat bahasa ibunda mereka, tanpa mereka sedari atau sebaliknya, dan berlakulah campur kod. Jadual 2 adalah data berkaitan tahap pendidikan dan aliran pendidikan responden.

JADUAL 2 Tahap Pendidikan dan Aliran Pendidikan Responden

\begin{tabular}{ccc} 
& JADUAL 2 Tahap Pendidikan dan Aliran Pendidikan Responden \\
\hline & Darjah 6 & $79(7.6 \%)$ \\
& Tingkatan 3 & $84(8.1 \%)$ \\
\multirow{5}{*}{ Akademik } & Tingkatan 5 & $250(24.2 \%)$ \\
& Tingkatan 6 & $159(15.4 \%)$ \\
& IPTA/IPTS & $462(44.6 \%)$ \\
\hline & Jumlah & $1035(100)$ \\
\hline \multirow{2}{*}{ Aliran Pendidikan } & Bahasa Inggeris & $145(14 \%)$ \\
& Bahasa Melayu & $890(86 \%)$ \\
\hline
\end{tabular}

Faktor amalan merujuk kepada kebiasaan responden menggunakan perkataan atau istilah daripada bahasa lain, berbanding bahasa ibundanya sendiri. Keadaan ini berlaku kerana istilah-istilah bahasa lain sudah biasa dan lazim digunakan, sama ada untuk mengatasi masalah peristilahan atau untuk mengatasi masalah terjemahan perkataan dalam bahasa ibunda yang terlalu panjang. Kekerapan penggunaan bahasa tersebut secara berterusan menyebabkan penggunaan perkataan tersebut dalam pertuturan menjadi suatu amalan. Hakikat ini membuktikan bahawa percampuran antara bahasa Melayu dan bahasa Inggeris dengan bahasa Iban bukanlah perkara yang janggal dalam kalangan penutur bahasa Iban. Valdès (1997), telah memberikan sedikit contoh percampuran kod yang melibatkan frasa dan klausa dari bahasa Spain ke bahasa Inggeris dan sebaliknya. Daripada contohnya dapat dirumuskan bahawa percampuran kod melibatkan sekurang-kurangnya satu patah perkataan dari bahasa asing disertakan 
dalam bahasa semasa. Pada ketika ini penyertaan satu patah kata dari bahasa lain ke bahasa penerima telah menjadi satu kebiasaan. Ini jelas menunjukkan bahawa faktor amalan memang menyumbang kepada situasi campur kod dalam komunikasi masyarakat Iban.

Faktor situasi sememangnya tidak dapat diketepikan jika membicarakan situasi campur kod dalam komunikasi masyarakat Iban. Hal ini kerana situasi campur kod ini sering berlaku dalam situasi tidak formal. Kesemua rakaman dalam kajian ini yang menunjukkan situasi campur kod berlaku, telah dirakam dalam situasi tidak formal, iaitu semasa berbual-bual di rumah panjang, di dalam kenderaan, dan sebagainya. Asmah (1982) membuat perbandingan fenomena alih kod yang berlaku dalam situasi formal dan tidak formal. Kajian tersebut adalah berkaitan dengan fenomena alih kod yang melibatkan bahasa Inggeris dan bahasa Melayu dalam situasi formal, dan alih kod yang melibatkan bahasa Melayu, bahasa Inggeris dan bahasa ibunda yang lain dalam situasi tidak formal. Asmah mendapati bahawa alih kod antara bahasa Melayu dan bahasa Inggeris sangat kerap dilakukan dalam situasi formal seperti dalam mesyuarat rasmi, manakala dalam situasi tidak formal pula, alih kod antara bahasa Melayu, bahasa Inggeris dan bahasa ibunda yang lain seperti bahasa Tamil, Kantonis serta dialek Melayu dikenal pasti sering dilakukan oleh masyarakat Malaysia secara umum. Oleh itu, dapatan kajian ini selari dengan dapatan Asmah (1982).

Faktor istilah mempengaruhi situasi campur kod dalam perbualan seharian masyarakat Iban. Kekurangan istilah dalam bahasa ibunda mendorong situasi campur kod ini berlaku. Penggunaan istilahistilah bahasa lain dalam pertuturan secara tidak langsung mewujudkan situasi campur kod. Lazimnya penggunaan beberapa istilah bahasa asing dalam pertuturan penutur jati bahasa Iban dilakukan kerana tiada atau kekurangan istilah yang sesuai ketika berbual tentang perkara-perkara seperti topik ekonomi, sains, politik dan sebagainya. Tindakan memasukkan beberapa istilah asing dalam pertuturan ini dapat memudahkan lagi proses komunikasi. Namun, untuk berbual tentang perkara yang berkaitan dengan aktiviti seharian dan perkara-perkara yang lazim dialami oleh masyarakat ini, tidak memerlukan si penuturnya menggunakan istilah bahasa lain kerana banyak istilah dalam bahasa Iban itu sendiri. Jadual 3 menunjukkan istilah-istilah bahasa lain yang digunakan dalam pertuturan semasa sesi rakaman untuk menangani masalah ketiadaan istilah yang sesuai dalam bahasa ibunda.

JADUAL 3 Istilah Bahasa Lain dalam Pertuturan Bahasa Iban

\begin{tabular}{lll}
\hline Bil. & No. Rakaman & Istilah bahasa lain \\
\hline 1 & Rakaman 2 & laptop \\
2 & Rakaman 7 & tile \\
3 & Rakaman 8 & masker, wire netting \\
4 & Rakaman 11 & workshop \\
5 & Rakaman 13 & steady \\
6 & Rakaman 14 & kontena \\
\hline
\end{tabular}

Selain itu, pengkaji mendapati bahawa faktor ungkapan yang panjang juga menyumbang kepada berlakunya situasi campur kod dalam komunikasi masyarakat Iban. Adanya istilah atau perkataan yang lebih pendek dan ringkas dalam bahasa lain yang dikuasai oleh penutur tersebut, menyebabkan penutur tersebut cenderung menggunakan istilah atau perkataan yang lebih pendek dan ringkas demi melancarkan komunikasinya. Pemilihan sesetengah perkataan dilihat lebih ekonomis dari segi bahasanya, maka tidak hairanlah penggunaan perkataan-perkataan tersebut menjadi satu kebiasaan dalam komunikasi harian. Oleh yang demikian, sifat ekonomis morfologi bahasa Melayu dan bahasa Inggeris menjadi alasan kepada berlakunya percampuran kod dalam pertuturan bahasa Iban. Jadual 4 memaparkan contoh-contoh yang berkaitan. 
JADUAL 4 Data Rakaman tentang Ungkapan yang Panjang

\begin{tabular}{cccc}
\hline Bil. & $\begin{array}{c}\text { Nombor Data } \\
\text { Rakaman }\end{array}$ & $\begin{array}{c}\text { Istilah Dalam Bahasa Melayu/ } \\
\text { Bahasa Inggeris }\end{array}$ & $\begin{array}{c}\text { Terjemahan Istilah Dalam Bahasa } \\
\text { Iban }\end{array}$ \\
\hline 1 & Rakaman 1 & Murum Dam & tekat ai Murum \\
2 & Rakaman 3 & paksalah & ka pan enda \\
3 & Rakaman 6 & tuisyen & kelas tambah \\
4 & Rakaman 6 & enjoy & ngelantangka ati \\
5 & Rakaman 7 & jiran & orang sepiak \\
6 & Rakaman 8 & sebenar & iya ke bendar \\
7 & Rakaman 13 & persediaan & utai ti disendiaka \\
\hline
\end{tabular}

Faktor ketepatan mesej memainkan peranan penting dalam situasi campur kod komunikasi bahasa Iban. Penggunaan bahasa lain selain daripada bahasa Iban dalam sesuatu perbualan dilihat mampu menyampaikan mesej dengan lebih tepat lagi. Malah ada yang berpendapat bahawa tidak mengira dengan cara apa sekalipun sesuatu mesej itu disampaikan, perkara yang utama ialah maklumat yang ingin disampaikan difahami oleh penerimanya. Malah, semasa bertutur menggunakan bahasa ibunda, individu tersebut menyelitkan bahasa lain, dan kemudiannya kembali menggunakan bahasa ibunda, dan begitulah seterusnya. Hal ini menunjukkan bahawa penutur tersebut menggunakan bahasa lain untuk mengungkapkan makna yang tidak diketahuinya dalam bahasa ibunda. Kekurangan pengetahuan atau tidak tahu sesetengah perkataan dalam bahasa yang sedang dituturkan menyebabkan berlakunya pemilihan bahasa lain sebagai alternatif untuk menyebut perkataan yang tidak diketahui dalam bahasa yang sedang dituturkan itu (Appel \& Muysken, 1990:172). Maka wujudlah percampuran kod dalam ayat penutur tersebut. Dapatan ini jelas dibuktikan dalam beberapa data rakaman pada Jadual 5, berdasarkan kekerapan campur kod yang dilakukan oleh penutur jati bahasa Iban.

JADUAL 5 Data Rakaman Tentang Ketepatan Mesej

\begin{tabular}{ccl}
\hline Bil. & $\begin{array}{c}\text { Nombor Data } \\
\text { Rakaman }\end{array}$ & \multicolumn{1}{c}{ Campur Kod Untuk Ketepatan Mesej } \\
\hline 1 & Rakaman 2 & Bisi, bisi iya ngambi, dah save Rin dalam laptop. \\
& Yalah, dah disave dalam laptop, dah disave sehari nya. \\
& Rakaman 9 & Ingu nya lah nuchuk indai iya kencing manis diatu. \\
& Au, indai iya kena kencing manis. \\
& & $\begin{array}{l}\text { Sampai diatu makai nya iya, nadai entu nya agi iya,kencing manis agi, } \\
\text { nadai entu tuchuk agi, gerai. Abi ke tuchuk nya gerai dih. }\end{array}$ \\
\hline
\end{tabular}

Penggunaan perkataan save dan laptop dalam rakaman 2 jelas bertujuan untuk ketepatan mesej kerana penggunaan perkataan-perkataan tersebut memudahkan makna dalam perbualan tersebut disampaikan dan difahami. Begitu juga dengan perkataan kencing manis dalam rakaman 9. Penggunaan bahasa lain adalah bertujuan untuk mendapatkan keberkesanan atau ketepatan mesej yang cuba disampaikan, di samping dapat mencerminkan pengetahuan individu tersebut terhadap perkara yang dibualkan. Tanpa padanan istilah yang sesuai dalam bahasa ibunda, serta beranggapan bahawa istilah dalam bahasa ibunda adalah kurang tepat dengan maksud sebenar yang ingin disampaikan, maka istilah dalam bahasa lain digunakan untuk memberi kesan yang lebih tepat dan bermakna kepada pendengar. Lazimnya, bahasa Melayu dan bahasa Inggeris sering digunakan untuk mengatasi situasi ini. 


\section{KESIMPULAN}

Ciri percampuran kod yang utama adalah penutur itu merupakan penutur dwibahasa atau multibahasa. Ini bermaksud penutur tersebut mempunyai pengetahuan variasi bahasa lebih daripada satu. Ciri-ciri percampuran kod dapat dilihat dari aspek kelicinan perbualan penutur tersebut. Ini bermaksud, penutur dapat berbual dengan spontan dan mengekalkan kelicinan perbualan setiap kali percampuran kod berlaku, maka tidak wujud perubahan dari segi irama ayat atau jeda untuk menandakan percampuran kod. Situasi ini juga tidak menunjukkan tanda bahawa penutur itu tidak memahami apa yang dicakapkannya. Percampuran kod berlaku kerana dipengaruhi oleh keadaan tertentu.

\section{RUJUKAN}

Appel, R. \& P. Muysken. (1990). Language contact and bilingualism. London: Edward Arnold.

Asmah Omar. (1982). Language and society in Malaysia. Kuala Lumpur: Dewan Bahasa dan Pustaka.

Babbie, E. (1998). Survey research methods ( $2^{\text {nd }}$ ed.). Belmont: Wadsworth. Ch. 3.

Chemaline Osup. (2011). Waris daya idup Iban Vol. 1. Bintulu: PEGARI Iban Production.

Creswell, J.W. \& Clark, V.L.P. (2007). Designing and conducting mix method research. California: Sage Publications.

Fasold, R. (1984). Sociolinguistics of society. Oxford: Blackwell.

Ghazali, S. (2003). Kut (informal rotating credit) in the livelihood strategies of urban households in Penang, Malaysia, AREA 35 (2).

Gomes, E.H. (2013). Seventeen years among the sea Dayaks of Borneo: a record of intimate association with the nations of the Bornean jungles. Primary Source Edition. Bibliobazaar.

Hymes, D. (1973). Toward linguistic competence. Texas working papers in sociolinguistics number 16. Austin: University of Texas, Dept. of Anthropology.

Pakir, Anne. (1989). Linguistic alternations and code selection in Baba Malay. World Englishes, Vol. 8, No.3,37988.

Sekaran, U. (2003). Research methods for business: A skill buildings approach. (4th ed.). Singapore: John Wileys Sons, Inc.

Valdès, G. (1997). The teaching of Spanish to bilingual Spanish-speaking students: Outstanding issues and unanswered questions. In M. C. Colombi \& F. X. Alarcon (Eds.), La ensenanza del espanol a hispanohablantes: Praxis y teoria (pp. 8-45). Boston, MA: Houghton Mifflin. 